\title{
Single Active Element Based Three input Single output Trans-admittance mode Biquad Universal Filter
}

\author{
Sajai Vir Singh ${ }^{\# 1}$,Chandra Shankar ${ }^{* 2}$, \\ \# Dept. of Electronics and Communication Engineering \\ Jaypee Institute of Information Technology, Noida, 201304, INDIA \\ *Dept. of Electronics Engineering, \\ JSS Academy of Technical Education Noida, 201301, INDIA \\ 1sajaivir75@gmail.com \\ 2porwalchandra@gmail.com
}

\begin{abstract}
In this paper, a new three input single output trans-admittance mode biquad universal filter is proposed, which employs only single active element, namely modified differential voltage current conveyor trans-conductance amplifier (MDVCCTA) and four passive elements in the form of two capacitors and two resistors. Two of the passive elements used in the proposed structure (one resistor and one capacitor) are permanently grounded. The proposed circuit is capable of realizing trans-admittancemode low pass (LP), high pass (HP), band pass (BP), band reject (BR) and all pass (AP) filtering responses. The two filter parameters such as quality factor and bandwidth are electronically tunable without effecting the pole frequency. In addition, the proposed filter circuit also enjoys the low active and passive sensitivities. PSPICE simulation results using 0.35 um CMOS technology are shown to prove the performances of the proposed circuit.
\end{abstract}

Keyword- Trans-admittance-mode, analog signal processing, filter, biquad, DVCCTA.

\section{INTRODUCTION}

In the last few decades, the current-mode approach of signal processing in designing of analog filters has offered an elegant solution due to their high performance attributes such as wider signal bandwidth, low power consumption, larger dynamic range, better linearity, simple circuitry and requirement of lesser on chip area [1][2] and hence, various current-mode active elements and their applications in analog filter design in various mode are proposed in the literature [3]-[24]. Among them, trans-admittance mode filter is one which convert input voltage signal into current signal as its output and can be effectively used as an interface circuit connecting a voltage-mode circuit to a current-mode circuit and find direct applications in some sensors, the receiver base band (BB) blocks of modern radio systems and D/A converters which provide a current as output signal [12][13].

A variety of works on realizing trans-admittance mode universal filters classified as single input multi output (SIMO) or multi input single output (MISO) are proposed in the available literature [13]-[24]. Among them, most of the trans-admittance-mode filter configurations require two ([13]-[14], [17], [22]) or more active elements (three in case of [15]-[16], [18], four in case of [19]-[20], five in case of [21]) in realization of various filtering functions.

As far as the topic of this paper is concerned, trans-admittance-mode biquad circuits using single active element are of great interest because circuits employing minimum (single) active components are more beneficial in terms of power dissipation and manufacturing cost point of view and also satisfy the supply related specifications of portable battery operated electronic gadgets. Two of the trans-admittance-mode filter circuits employing single active element as VDTA are also found in the available literature [23]-[24]. Each of the reported circuits uses one resistor and two capacitors. One of the circuits [23] realizes only two filtering functions (HP, LP) whereas other one realizes four filtering functions (LP, BP, HP, BR) with three of the filtering outputs were obtained on passive elements [24]. Hence, number of additional current conveyor(s) will be further required to implement all the standard universal filter functions (LP, HP, BP, BR and AP).

Keeping above discussion in the mind, a filter topology based on minimum number of active element as MDVCCTA is proposed in this paper which can realize all the five standard filtering functions in transadmittance-mode. In addition to single active element, the proposed structure also consists of four passive elements in the form of two capacitors and two resistors. Moreover, the proposed filter circuit provides the feature of electronic tunability of filter parameters and low active passive sensitivity. The rest of the paper is organized as description of active element as MDVCCTA is given in section II. The description of proposed filter circuit followed by non ideal analysis and sensitivity analysis is given in section III and IV. Simulated results are shown in section V. Finally, the paper is concluded in section VI. 


\section{DESCRIPTION OF MDVCCTA}

Recently DVCCTA have been extensively used as current-mode active element in designing of analog circuits [7], [25]-[26]. Modified DVCCTA (MDVCCTA) is the modified version of recently proposed DVCCTA and offers the additional electronic tunability option over conventional DVCCTA. The schematic symbol of MDVCCTA is shown in Fig. 1. The input port $X$ is a low impedance port and transfers the copy of its current $\left(I_{X}\right)$ to two auxiliary ports $Z_{1}$ and $Z_{2}$. The input ports $Y_{1}$ and $Y_{2}$ are input high impedance ports and ideally current in these ports is equal to zero. The voltages across auxiliary ports at $Z_{1}$ and $Z_{2}$ are transferred to currents $\mathrm{I}_{\mathrm{O} 1}$ and $\mathrm{I}_{\mathrm{O} 2}$ across high impedance output ports $\mathrm{O}_{1}$ and $\mathrm{O}_{2}$, respectively, by trans-conductance parameter $\mathrm{g}_{\mathrm{m} 1}$ and $\mathrm{g}_{\mathrm{m} 2}$, respectively. Both trans-conductance parameters $\mathrm{g}_{\mathrm{m} 1}$ and $\mathrm{g}_{\mathrm{m} 2}$ are electronically controlled by biasing currents $\mathrm{I}_{\mathrm{S} 1}$ and $\mathrm{I}_{\mathrm{S} 2}$ of the MDVCCTA. The ideal equations governing relationship of voltages and currents between various input-output ports of MDVCCTA as shown in Fig. 1 can be described as

$$
\begin{gathered}
V_{X}=V_{Y 1}-V_{Y 2} \\
I_{Z 1}=I_{Z 2}=I_{X} \\
I_{-O 1}=-g_{m 1} V_{Z 1} \\
I_{-O 2}=-g_{m 2} V_{Z 2}
\end{gathered}
$$

The internal circuit of MDVCCTA, implemented with CMOS technology is shown in Fig. 2. For the CMOS realization, the value of $g_{\mathrm{m} 1}$ and $g_{\mathrm{m} 2}$ as a function of biasing currents $I_{\mathrm{S} 1}$ and $\mathrm{I}_{\mathrm{S} 2}$, respectively, can be derived as following equations.

$$
\begin{gathered}
g_{m 1}=\sqrt{\beta_{n} I_{S 1}} \text { and } g_{m 2}=\sqrt{\beta_{n} I_{S 2}} \\
\beta_{n}=\mu_{n} C_{O X} \frac{W}{L}
\end{gathered}
$$

Here, $\mu$ is the electron mobility, $\mathrm{C}_{\mathrm{OX}}$ is the gate oxide capacitance per unit area and $\mathrm{W} / \mathrm{L}$ is aspect ratio of NMOS transistors $\mathrm{M}_{17}-\mathrm{M}_{18}$ and $\mathrm{M}_{23}-\mathrm{M}_{24}$.

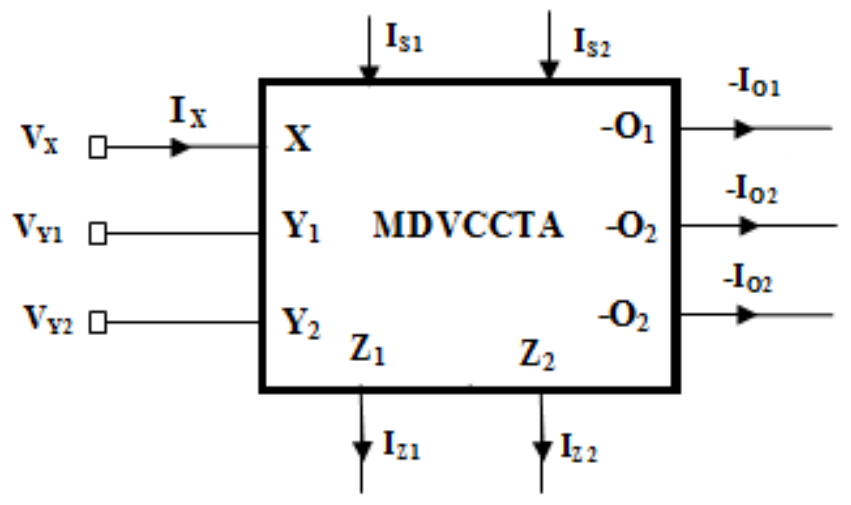

Fig. 1. Schematic symbol of DVCCTA

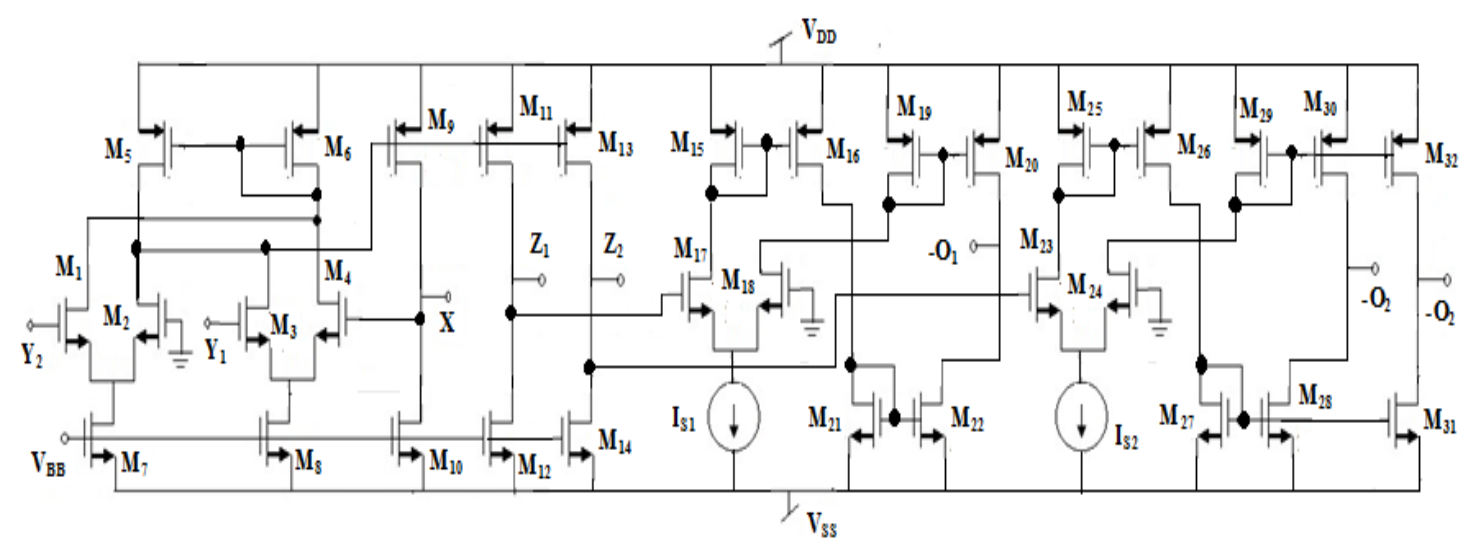

Fig.2. CMOS implementation of MDVCCTA 


\section{Proposed Trans-admittance MODE BIQUAD Filter}

The proposed trans-admittance biquad filter is shown in Fig.3. It consists of only single MDVCCTA, two capacitors $\left(C_{1}\right.$ and $\left.C_{2}\right)$ and two resistors $\left(R_{1}\right.$ and $\left.R_{2}\right)$ with one capacitor $\left(C_{1}\right)$ and one resistor $\left(R_{2}\right)$ are being permanently grounded. By applying $\mathrm{V}_{1}, \mathrm{~V}_{2}$, and $\mathrm{V}_{3}$ as voltage input signals to the appropriate positions in the circuit as shown in Fig. 3 and re-analysing the circuit, the following expression for the output current $I_{\mathrm{OUT}}$ can be obtained.

$$
I_{\text {OUT }}=-g_{m 2} \frac{V_{3} D(s)-R_{1}\left(V_{2} s^{2} C_{1} C_{2}+V_{1} s g_{m 1} C_{2}+V_{3} s g_{m 2} C_{2}\right)}{D(s)}
$$

Where

$$
D(s)=s^{2} C_{1} C_{2} R_{2}+s C_{2} R_{1} g_{m 2}+g_{m 1}
$$

It is evident from above equations that the following trans-admittance-mode filtering responses can be obtained at $I_{\mathrm{OUT}}$ by the appropriate selection of $\mathrm{V}_{1}, \mathrm{~V}_{2}$ and $\mathrm{V}_{3}$.

$\begin{array}{ll}\text { i. } & \text { LP filtering response when } \mathrm{V}_{2}=\mathrm{V}_{3}=1, \mathrm{~V}_{1}=0 \text { and } \mathrm{R}_{1}=\mathrm{R}_{2} . \\ \text { ii. } & \text { BP filtering response when } \mathrm{V}_{1}=1 \text { and } \mathrm{V}_{2}=\mathrm{V}_{3}=0 . \\ \text { iii. } & \text { HP filtering response when } \mathrm{V}_{2}=1 \text { and } \mathrm{V}_{1}=\mathrm{V}_{3}=0 . \\ \text { iv. } & \text { BR filtering response when } \mathrm{V}_{3}=1 \text { and } \mathrm{V}_{1}=\mathrm{V}_{2}=0 . \\ \text { v. } & \text { AP filtering response when } \mathrm{V}_{1}=\mathrm{V}_{3}=1, \mathrm{~V}_{2}=0 \text { and } \mathrm{g}_{\mathrm{m} 1}=\mathrm{g}_{\mathrm{m} 2} .\end{array}$

Thus, the proposed circuit can realize all five filtering responses in trans-admittance-mode without requiring any inverted and/or scaled type voltage input signal(s). However, LP filtering and AP filtering responses require simple matching condition which can be justified in light of single active element used in the design of proposed biquad filter.

From $D(\mathrm{~s})$ described in equation (6), the expression of filter parameters such as pole frequency $\left(\omega_{0}\right)$, quality factor $(\mathrm{Q})$ and bandwidth $(\mathrm{BW})$ can be derived as

$$
\begin{gathered}
\omega_{o}=\sqrt{\frac{g_{m 1}}{C_{1} C_{2} \mathrm{R}_{2}}}=\sqrt{\frac{1}{C_{1} C_{2} R_{2}} \sqrt{\beta_{n} I_{S 1}}} \\
Q=\frac{1}{R_{1} g_{m 2}} \sqrt{\frac{C_{1} R_{2} g_{m 1}}{C_{2}}}=\frac{1}{R_{1}} \sqrt{\frac{C_{1} R_{2}}{C_{2} I_{S 2}} \sqrt{\frac{I_{S 1}}{\beta_{n}}}} \\
B W=\frac{\omega_{o}}{Q}=\frac{g_{m 2}}{C_{1}} \frac{R_{1}}{R_{2}}=\frac{1}{C_{1}} \frac{R_{1}}{R_{2}} \sqrt{\beta_{n} I_{S 2}}
\end{gathered}
$$

It can be noted from (9)-(11) that the $Q$ and BW can be electronically tunable without effecting $\omega_{0}$ through single biasing current $\mathrm{I}_{\mathrm{S} 2}$ only.

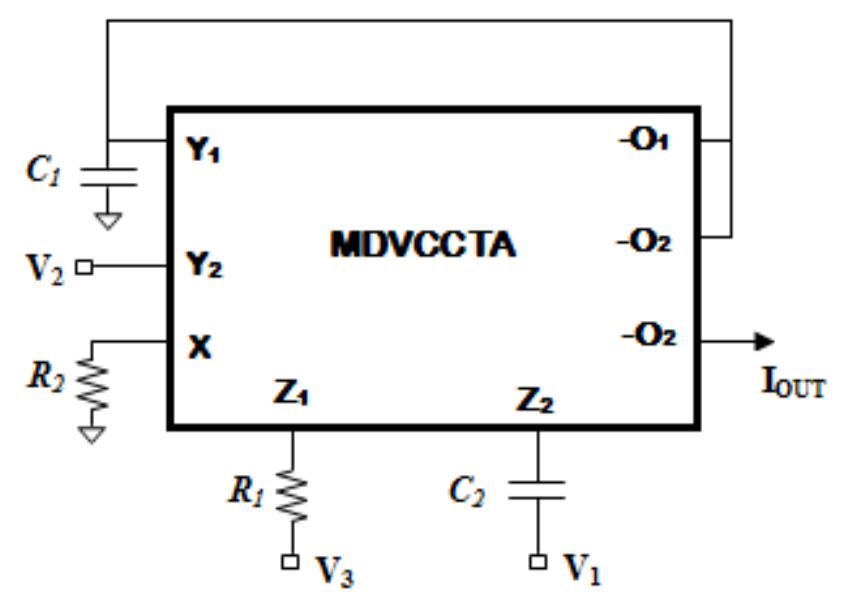

Fig. 3. Trans-admittance mode Biquad Filter 


\section{NON IDEAL BEHAVIOUR AND SENSITIVITY ANALYSIS}

In this section, the effect of non ideal errors on the performance of the proposed filter circuit of Fig. 3, which may occurred due to mismatching of the various MOS transistors used in CMOS implementation of MDVCCTA, is considered first.

Taking these non-ideal errors into consideration, the voltage-current port relationship of MDVCCTA will be modified as described below

$$
\begin{aligned}
& V_{X}=\beta_{1} V_{Y 1}-\beta_{2} V_{Y 2} \\
& I_{Z 1}=\alpha_{1} I_{X} \\
& I_{Z 2}=\alpha_{2} I_{X} \\
& I_{-O 1}=-\gamma_{1} g_{m 1} V_{Z 1} \\
& I_{-O 2}=-\gamma_{2} g_{m 2} V_{Z 2}
\end{aligned}
$$

Where $\alpha_{1}$ and $\alpha_{2}$ are the current tracking errors from $X$ to $Z_{1}$ and $Z_{2}$, respectively. The $\beta_{1}$ and $\beta_{2}$ are the voltage tracking errors from $Y_{1}$ to $X$ and $Y_{2}$ to $X$, respectively. The $\gamma_{1}$ and $\gamma_{2}$ are the trans-admittance gain tracking errors from $Z_{1}$ to $O_{1}$ and $Z_{2}$ to $O_{2}$, respectively, which may be deviated from unity. Taking above nonidealities into consideration, if we re-analysed the proposed circuit of Fig. 3, the following output equations for the $I_{\text {OUT }}$ can be obtained.

$$
I_{\text {OUT }}=-\gamma_{2} g_{m 2} \frac{V_{3} D(s)-R_{1} \alpha_{2}\left(V_{2} s^{2} \beta_{2} C_{1} C_{2}+V_{1} s \beta_{1} \alpha_{1} g_{m 1} C_{2}+V_{3} s \beta_{1} \gamma_{2} g_{m 2} C_{2}\right)}{D(s)}
$$

where

$$
D(s)=s^{2} C_{1} C_{2} R_{2}+s \alpha_{2} \beta_{1} \gamma_{2} C_{2} R_{1} g_{m 2}+\alpha_{1} \beta_{1} \gamma_{1} g_{m 1}
$$

The filters parameters of the circuit after considering tracking errors at various ports will be changed to

$$
\begin{gathered}
\omega_{o}=\sqrt{\frac{\alpha_{1} \beta_{1} \gamma_{1} g_{m 1}}{C_{1} C_{2} R_{2}}} \\
Q=\frac{1}{\alpha_{2} \gamma_{2} R_{1} g_{m 2}} \sqrt{\frac{\alpha_{1} \gamma_{1} C_{1} R_{2} g_{m 1}}{\beta_{1} C_{2}}}
\end{gathered}
$$

It is clear from (19)-(20) that $\omega_{0}$ and Q of the proposed filter of Fig. 3 will be deviated from the ideal case, due to the appearance of non-idealties. However, these deviations are very slight and can be neglected because non ideal parameters $\alpha_{1}, \alpha_{2}, \beta_{1}, \beta_{2}, \gamma_{1}$ and $\gamma_{2}$ can be found closed to unity at working frequency.

The sensitivities of the proposed circuit's pole frequency and quality factor with respect to various non ideal errors, active and passive components are determined as

$$
\begin{aligned}
& S_{\alpha_{1}, \beta_{1}, \gamma_{1}, g_{m l}}^{\omega_{o}}=\frac{1}{2}, S_{C_{1}, C_{2}, R_{2}}^{\omega_{o}}=-\frac{1}{2}, S_{\alpha_{2}, \beta_{2}, \gamma_{2}, R_{1}}^{\omega_{o}}=0 \\
& S_{C_{2}, \beta_{1}}^{Q}=-\frac{1}{2}, S_{C_{1}, \alpha_{1}, \gamma_{1}, R_{2}, g_{m l}}^{Q}=\frac{1}{2}, S_{\alpha_{2}, \gamma_{2}, R_{1}, g_{m 2}}^{Q}=-1
\end{aligned}
$$

Evaluation of circuit in (21)-(22) for sensitivity shows that $\omega_{0}$ and $Q$ are less sensitive to non ideal errors, active and passive components and for them sensitivity value is less than or equal to unity in magnitude.

\section{Simulation Results}

To verify the theoretical analysis of the proposed filter done in section II, PSPICE simulation on ORCAD tool was carried out. For this purpose, the circuit was designed by selecting the value of various active and passive elements as $\mathrm{V}_{\mathrm{DD}}=-\mathrm{V}_{\mathrm{SS}}=1.85 \mathrm{~V}, \mathrm{~V}_{\mathrm{BB}}=-0.85 \mathrm{~V}, \mathrm{I}_{\mathrm{S} 1}=\mathrm{I}_{\mathrm{S} 2}=110 \mu \mathrm{A}, \mathrm{C}_{1}=\mathrm{C}_{2}=80 \mathrm{pF}, \mathrm{R}_{1}=\mathrm{R}_{2}=2 \mathrm{~K} \Omega$ and simulated was performed based on CMOS structure of MDVCCTA as shown in Fig. 2, with transistor model of $0.35 \mu \mathrm{m}$ MOSFET from TSMC. Aspect ratio of each MOS transistors of MDVCCTA used for simulation is given in Table 1. Fig. 4 and Fig. 5 shows the simulation results in term of magnitude and phase response of LP, BP, HP, $\mathrm{BR}$ and AP for the proposed trans-admittance-mode filter of Fig. 3. From the simulation results shown in Fig. 4 and Fig. 5, the pole frequency was obtained as $1.0965 \mathrm{MHz}$ which is very much closed to designed pole 
frequency of $1.07 \mathrm{MHz}$. The power dissipation of the proposed circuit is $2.65 \mathrm{~mW}$. In order to show the electronic tuning feature of $\mathrm{Q}$ independent of pole frequency for the proposed filter, the circuit was further simulated to obtain various $\mathrm{BP}$ responses at different value of $\mathrm{I}_{\mathrm{S} 2}$ and corresponding simulation results was shown in Fig. 6. From the Fig. 6, Q value was found (at constant pole frequency of $1.0965 \mathrm{MHz}$.) as 2.1, 1.08, 0.768 and 0.56 , respectively, at different values of $\mathrm{I}_{\mathrm{S} 2}=20 \mu \mathrm{A}, 80 \mu \mathrm{A}, 160 \mu \mathrm{A}$ and $300 \mu \mathrm{A}$, respectively, which proves the electronic tunable capability of the proposed circuit.

To examine the total harmonic distortion (THD) produce by the circuit, the circuit was again simulated for THD analysis at HP, by applying sinusoidal input voltage of varying amplitude and constant frequency. The THD values at frequency of $10 \mathrm{MHz}$ are shown in Fig. 7 which clearly shows that for the input voltage signal having amplitude less than $160 \mathrm{mV}$, the THD remains in acceptable limits i.e. 3\%. Lastly, the time domain behavior of HP response with respect to sinusoidal input voltage is shown in Fig. 8. It is clear from the simulations that $100 \mathrm{mV}$ peak-to-peak sinusoidal input voltages are possible without significant distortions.

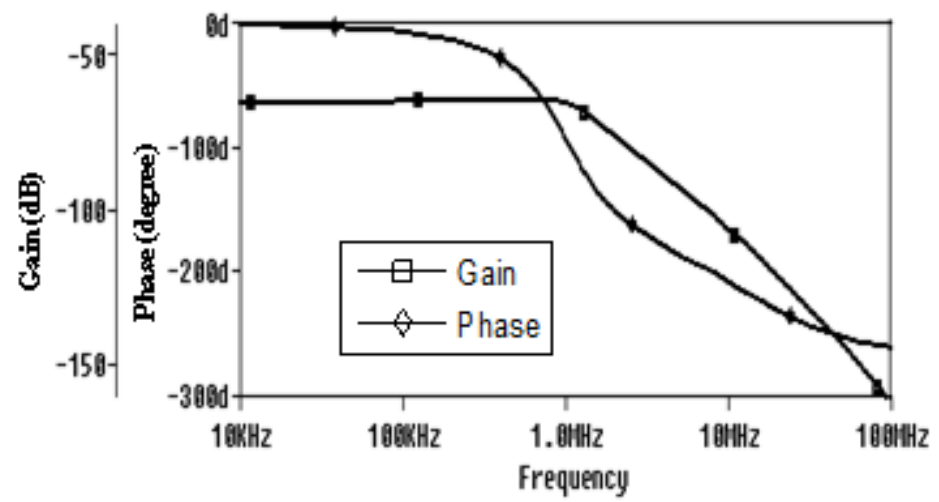

(a)

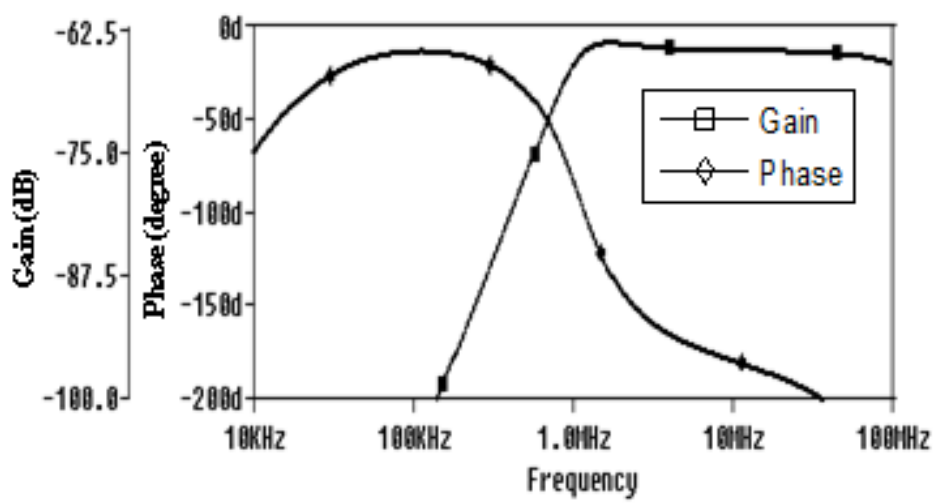

(b)

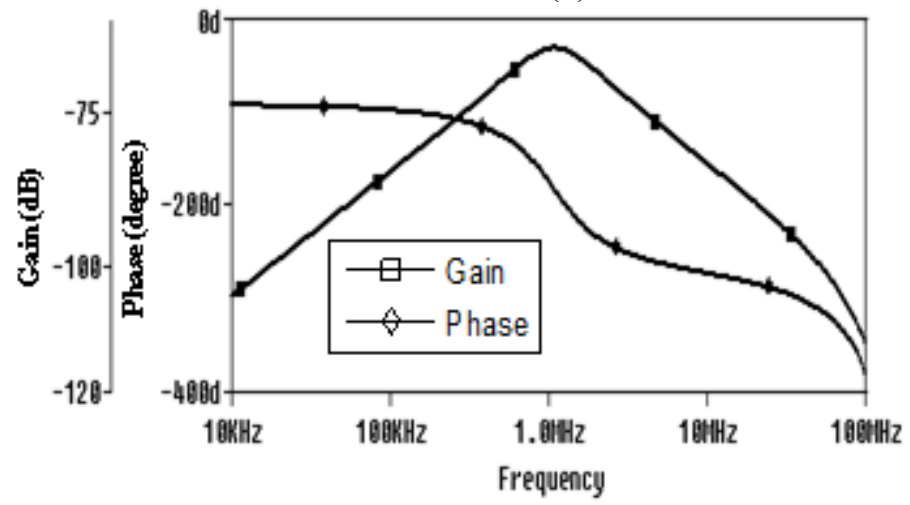

(c) 


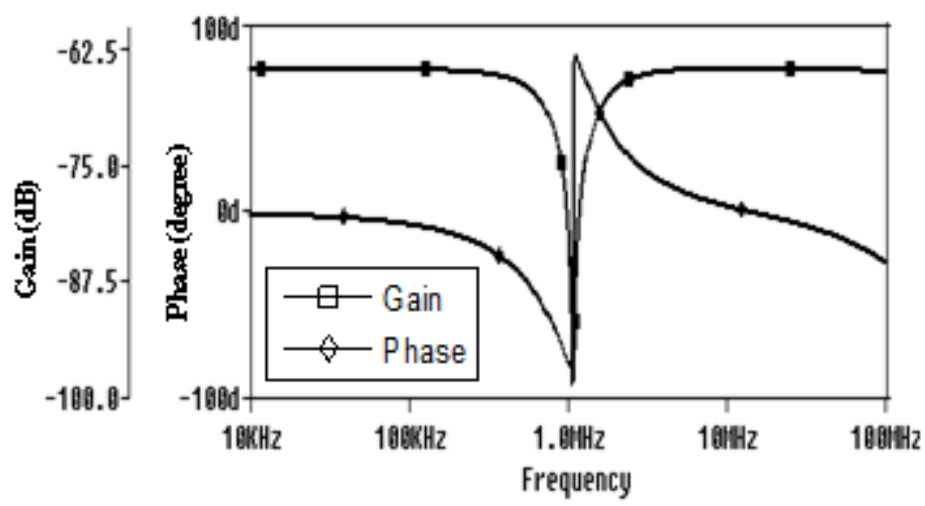

(d)

Fig .4 .Simulated gain and phase response of the proposed trans-admittance mode biquad filter : (a) LP, (b) HP, (c) BP (d) BR

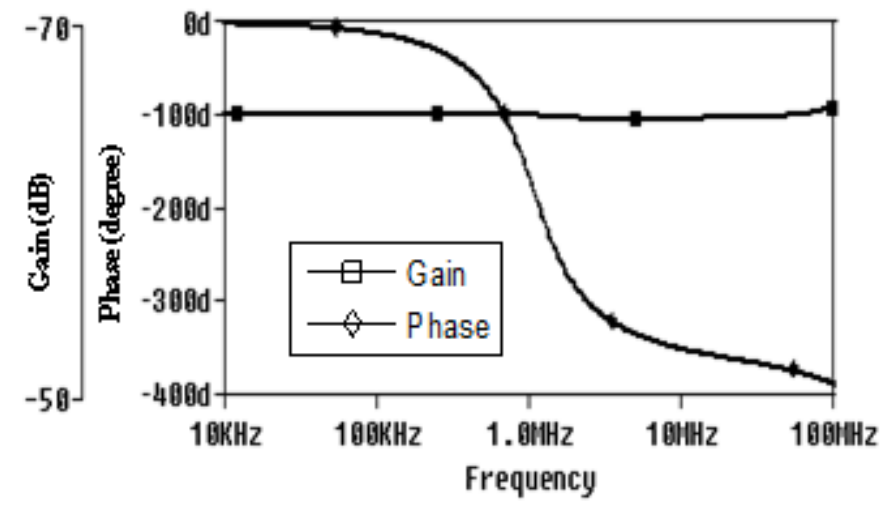

Fig. 5. Simulated gain and phase response of the proposed trans-admittance mode AP biquad filter.

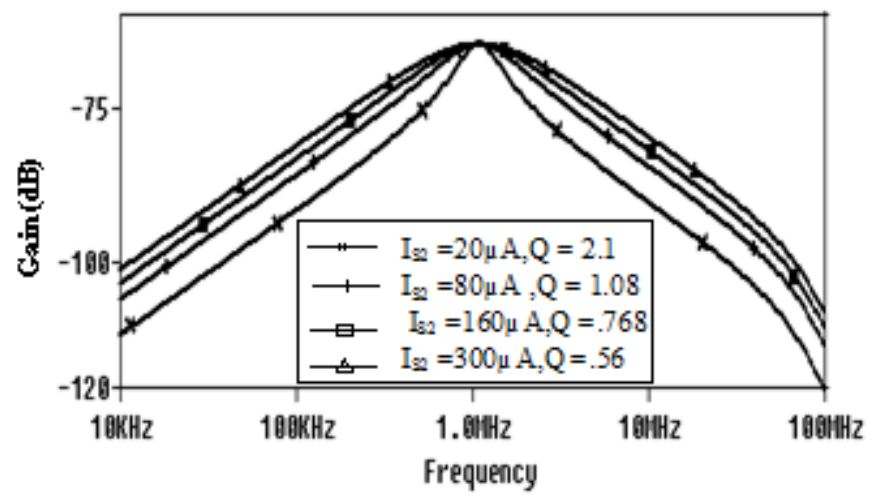

Fig.6. Band pass responses for different values of $\mathrm{I}_{\mathrm{s} 2}$.

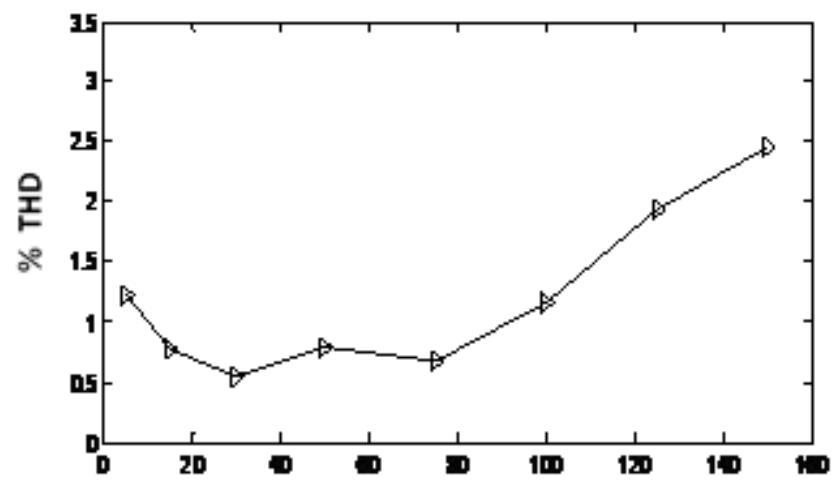

Fig. 7. Variation in THD of HP for input signal of frequency 10MHz. 


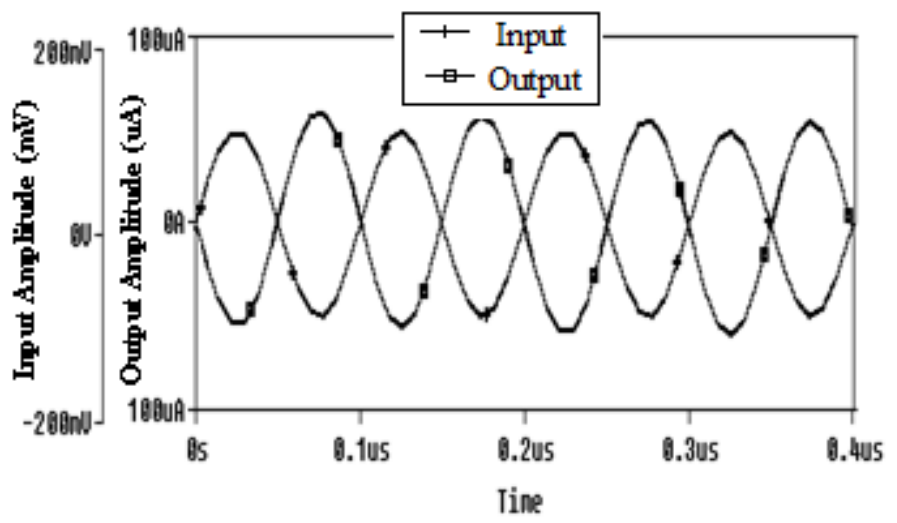

Fig.8. The time domain sinusoidal input waveform and corresponding response at HP output of Fig.3.

TABLE II. TRANSISTOR TYPE AND ASPECT RATIOS

\begin{tabular}{|c|l|c|}
\hline \multirow{2}{*}{ Transistor Type } & \multicolumn{1}{|c|}{ Transistor Number } & \multicolumn{1}{|c|}{$\begin{array}{c}\text { Aspect ratio } \\
(\mathbf{W}(\boldsymbol{\mu} \mathbf{m}) / \mathbf{L}(\boldsymbol{\mu} \mathbf{m}))\end{array}$} \\
\hline \multirow{2}{*}{ nMOS } & M1-M4, M7-M8,M10, M12, M14 & $5 / 1$ \\
\cline { 2 - 3 } & M17-M18, M21-M24, M27-M28, M31 & $20 / 1$ \\
\hline \multirow{2}{*}{ pMOS } & $\begin{array}{l}\text { M5, M6, M9,M11, M13,M15-M16,M19- } \\
\text { M20,M25- M26, M29-M30, M32 }\end{array}$ & $10 / 1$ \\
\hline
\end{tabular}

\section{CONCLUSION}

A new three input single output trans-admittance mode biquad universal filter based on only single active element namely MDVCCTA is proposed in this work. It also uses two capacitors and two resistors as passive element with two of the passive elements (one capacitor and one resistor) are permanently grounded. In addition, the proposed circuit offers the following attractive features.

i. Capable of realizing LP, BP, HP, BR, AP filtering responses in trans-admittance-mode.

ii. The circuit is canonical by the way of using only two capacitors.

iii. The circuit does not require any scaled or inverted type voltage signal to realize any filtering response which makes the circuit simpler.

iv. The circuit provide the feature of electronic control of Q and BW independent of $\omega_{0}$ through single biasing current and hence suited for practical applications.

v. Active and passive components sensitivity is low.

vi. Minimum number of active element.

vii. Low power consumptions.

\section{REFERENCES}

[1] B. Wilson, "Recent developments in current mode circuits," Proc. IEE., Pt. G, Vol. 137, pp. 63-77, 1990.

[2] G. W. Roberts and A. S. Sedra, "All current-mode frequency selective circuits," Electronics Letter, Vol. 25, pp. 759-761, 1989.

[3] S. Maheshwari, S. V. Singh and D. S. Chauhan, "Electronically tunable low voltage mixed-mode universal biquad filter, IET Circuits, Devices and Systems, Vol. 5, No. 3, pp. 149-158, 2011.

[4] S. V. Singh, R. S. Tomar and D. S. Chauhan, "ZC-CFTA based trans-impedance-mode universal biquad filter with electronic tuning," IEEE International Conference on Signal Processing and Integrated Network (SPIN-2014, Amity Univ. 20-21 Feb. 2014, Noida), pp. $543-548,2014$.

[5] A. Ü. Keskin, D. Biolek, E. Hancioglu and V. Biolkova, "Current-mode KHN filter employing current differencing transconductance amplifiers, Int'l J. Electronics and Communications (AEÜ)," Vol. 60, pp. 443-446, 2006.

[6] M. Soliman,” Mixed-mode biquad circuits," Journal of Microelectronics, Vol. 27, pp. 591-596, 1996.

[7] N. Pandey and S. K. Paul, "VM and CM universal filters based on single DVCCTA," Active and Passive Electronic Components, Vol. 2011, Article ID- 929507, doi:10.1155/2011/929507, pp. 1-7, 2011.

[8] R. S. Tomar, S. V. Singh and D. S. Chauhan, "Cascadable low voltage operated current-mode universal biquad filter," WSEAS Transactions on Signal Processing, Vol. 10, pp. 345-353, 2014.

[9] S. Maheshwari, "High performance voltage-mode multifunction filter with minimum component count," WSEAS Transations on Electronics, Vol. 5, pp. 244-249, 2008.

[10] S. Maheshwari, "High output impedance current-mode all-pass sections with two grounded passive components," IET Circuits Devices System, , Vol. 2, No. 2,pp. 234-242, 2008.

[11] H. P. Chen, "High-input impedance voltage-mode differential difference current conveyor transconductance amplifier-based universal filter with single input and five outputs using only grounded passive components," IET Circuits, Devices \& Systems, Vol. 8, No. 8, pp. 280-290, 2014. 
[12] N. A. Shah, S. Z. Iqbal and B. Parveen, "Lowpass and bandpass transadmittance filter using operational amplifier pole," AEU Int'1 J. Electronics and Communications, Vol. 59, No. 7, pp. 410-412, 2005.

[13] S. V. Singh, S. Maheshwari, J. Mohan and D. S. Chauhan, "An electronically tunable SIMO biquad filter using CCCCTA," Contemporary Computing, CCIS, Vol. 40, pp. 544-554, 2009.

[14] D. Prasad, M. Srivastava and D. R. Bhaskar, "Transadmittance type universal current-mode biquad filter using VDTAs,"International Scholary Research Notice, Vol. 2014, Article ID-762845, pp. 1-4, 2014.

[15] A. Toker, O. ÇiÇekoglu, S. Özcan and H. Kuntman, "High output impedance transadmittance type continuous time multifunction filter with minimum active elements, "Int'l J. Electronics, Vol. 88, No. 10, pp. 1085-1091, 2001.

[16] N. A. Shah, S. Z. Iqbal and B. Parveen, "SITO high output impedance transadmittance filter using FTFNs," Analog Integrated Circuits and Signal Processing, Vol. 40, No. 4, pp. 87-89, 2004.

[17] C. Shankar and S. V. Singh, "A new trans-admittance-mode biquad filter using MO-VDTAs," WSEAS Transactions on Circuits and Systems, Vol. 14, pp. 8-18, 2015.

[18] M. A. Ibrahim and H. Kuntman, "Transadmittance type KHN biquad employing DO-DDCC," Proc. Of ECCTD 2003 Europian Conf. On circuit theory and design, Vol. 1, pp. 279-282, 2003.

[19] D. R. Bhaskar, A. K. Singh, A. K. Sharma and R. Senani, "New OTA-C universal current-mode/trans-admittance biquads," IEICE Electronics Express, Vol. 2, pp. 8-13, 2005.

[20] M. A. Ibrahim and H. Kuntman," A novel transadmittance-type KHN biquad employing DO-OTA with only two grounded capacitors," Proc. IEEE $13^{\text {th }}$ Int'l Conf. Signal Processing and Communications Applications, pp. 119-122, 2005.

[21] P. Beg, S. Maheshwari and M. Siddiqi, "Digitally controlled fully differential voltage-and transadmittance-mode biquadratic filter," IET Circuits, Devices and Systems, Vol. 7, pp. 193-203, 2013.

[22] N. A. Shah, M. Quadri and S. Z. Iqbal, "CDTA based universal transadmittance filter,"Analog Integrated Circuits and Signal Processing, Vol. 52, pp. 65-69, 2007.

[23] C. Shankar and S. V. Singh, "A low voltage operable VDTA based biquad filter realizing band pass and high pass filtering functions in trans-admittance-mode," In Proc. of IEEE Int'l Conf. on Computing Communication and Automation (ICCCA 2015), pp. 1288$1293,2015$.

[24] C. Shankar and S. V. Singh, "Single VDTA based multifunction trans-admittance-mode biquad filter," Int"l J. of Engineering and Technology, Vol. 7, no. 6, pp. 2180-2188, Dec-2015- Jan 2016.

[25] A. Jantakun, N. Pisutthipong and M. Siripruchyanun, "A synthesis of temperature insensitive/electronically controllable floating simulators based on DV-CCTAs," $6^{\text {th }}$ IEEE Int'l Conf. on Electrical Engineering/Electronics, Computer, Telecommunication and Information Tech (ECTI-CON), pp. 560-563, 2009.

[26] A. Lahiri, W. Jaikla and M. Siripruchyanun, "Voltage-mode quadrature sinusoidal oscillator with current tunable properties, " Analog Integrated Circuit Signal Processing, Vol. 65, pp. 321-325, 2010.

\section{AUTHOR PROFILE}

Dr. Sajai Vir Singh was born in Agra, India. He received his B.E. degree in Electronics and Telecommunication from NIT Silchar, Assam (India), M.E. degree from MNIT Jaipur, Rajasthan (India) and Ph.D. degree) from Uttarakhand Technical University. He is currently working as Assistant Professor (Sr. Grade) in the Department of Electronics and Communication Engineering of Jaypee Institute of Information Technology, Noida (India) and has been engaged in teaching and design of courses related to the design and synthesis of Analog and Digital Electronic Circuits. He served as the reviewer of number of technical Int'l Journals like Micro electronics Journal, Active and Passive Electronic components, Circuits and Systems etc. He also served as the member of Technical Program Committee as well as session chair in number of IEEE Int'l Conferences. His research areas include Low Power CMOS Circuit Design, Digital and Analog CMOS Design, Current Mode Active Circuits Design and SRAM Memory Design. He has published more than 42 number of papers in various International Journals/Conferences.

Chandra Shankar was born in Etawah, India. He received his B.Tech degree in Electronics and Communication from GLAITM, Mathura (India), M.Tech. degree from CDAC, Mohali (India) and Pursuing $\mathrm{Ph} . \mathrm{D}$ from Jaypee Institute of Information Technology, Noida (India). He is working as an Asst. Professor in the Dept. of Electronics of JSS Academy of Technical Education Noida, (India). His area of interest is Analog Signal Processing and Circuit Designing. 